\title{
Neonatal Damage of the Ventral Hippocampus Impairs Working Memory in the Rat
}

\author{
Barbara K. Lipska, Ph.D., Julie M. Aultman, B.S., Anita Verma, Ph.D., Daniel R. Weinberger, M.D., \\ and Bita Moghaddam, Ph.D.
}

We investigated if a developmental lesion of the ventral hippocampus, studied previously as an animal model of schizophrenia, impairs performance in working memory tests related to the prefrontal cortex. Adult rats with a neonatal or adult excitotoxic lesion of the ventral hippocampus were tested in a continuous delayed alternation and a discrete paired-trial variable-delay alternation task. Performance of rats with the neonatal lesion was impaired as compared with control rats on both tasks, whereas performance of rats with the adult lesion was not altered in either task. The pattern of impaired

KEY WORDS: Working memory; Ventral hippocampus; Development; Prefrontal cortex; Neonatal lesion; Delayed alternation

Previous studies in the rat (for review see Lipska and Weinberger 2000) and in the monkey (Bertolino et al. 1997; Saunders et al. 1998; Weinberger et al. 2001) have demonstrated that animals with a neonatal lesion of the hippocampal formation display a variety of behavioral and cellular abnormalities reminiscent of schizophrenia, and can be used as an animal model of this disorder. Important aspects of this model in the rat are that the behavioral outcome of an early insult differs markedly from that seen after an analogous adult lesion, that cer-

From the From the Clinical Brain Disorders Branch, NIMH, IRP, Bethesda, MD 20892-1385 (BKL, DRW); Department of Psychiatry (JMA, AV, BM); and Department of Neurobiology (BM), Yale University School of Medicine, VAMC 116A/2, West Haven, CT 06516.

Address correspondence to: B.K. Lipska, Bldg.10, Rm. 4N306, Bethesda, MD 20892-1385, Tel.: (301) 496-9501, Fax: (301) 402-2751, E-mail: lipskab@intra.nimh.nih.gov

Received April 6, 2001; revised September 17, 2001; accepted December 4, 2001.

Online publication: $1 / 8 / 02$ at www.acnp.org/citations/ Npp010802220. performance, that worsened with increasing delays in neonatally lesioned rats, resembled that reported previously in animals with adult lesions of the medial prefrontal cortex. These results indicate that an early developmental, but not adult hippocampal, insult impairs performance in tasks sensitive to the integrity of the prefrontal cortex, and suggest that working memory may be compromised by neonatal damage of the ventral hippocampus.

[Neuropsychopharmacology 27:47-54, 2002]

(C) 2002 American College of Neuropsychopharmacology. Published by Elsevier Science Inc.

tain abnormal behaviors emerge only after puberty, and that their emergence is not dependent on the surge of gonadal hormones at the time of puberty (Lipska et al. 1993, 1995a,b; Swerdlow et al. 1995; Lipska and Weinberger 1994). We have, therefore, posited that aberrant functioning of the late maturing medial prefrontal cortex (mPFC) may be a neural substrate for the delayed emergence of at least some abnormal behaviors associated with the neonatal lesion of the rat ventral hippocampus.

Several lines of evidence suggest that the neonatal lesion of the ventral hippocampus in the rat compromises the architectural integrity of $\mathrm{mPFC}$, a region that receives extensive projections from the ventral hippocampus (Jay and Witter 1991; Carr and Sesack 1996). For example, this lesion decreases GAD 67 mRNA expression (Lipska and Weinberger 2000), n-acetylaspartate (NAA) concentrations (Bertolino et al. 1999) and spine density and dendritic length of mPFC pyramidal neurons (Lipska et al. 2000), and alters frontal cortical glutamatergic neurotransmission (i.e., specific glutamate binding is enhanced in the lesioned rats, Schroeder et al. 1999). The removal of presumably abnormal mPFC from adult rats with the neonatal hippocampal lesion appears to nor- 
malize some of the behavioral effects of this lesion (such as exaggerated novelty- and amphetamine-induced hyperlocomotion), suggesting that the dysfunctional mPFC may play a role in mediating these behaviors (Lipska et al. 1998). Complex behaviors thought to be dependent on the integrity of prefrontal cortex, such as social interactions, are also disrupted by the neonatal, but not adult, ventral hippocampal lesion (Sams-Dodd et al. 1997; Becker et al. 1999). Similarly, in monkeys with neonatal medial temporal removals (but not analogous ablations in adulthood), NAA concentrations are reduced in dorsolateral PFC (Bertolino et al. 1997), and the response of PFC to amphetamine is abnormal (Saunders et al. 1998). Moreover, neonatal lesions of medial temporal lobe region in the monkey disrupt specific memory processes and impair socioemotional behaviors in a fashion different from that after adult lesions (Bachevalier et al. 1999).

To the extent that MPFC in the rat parallels PFC in primates and humans (based on their relation to the dorsal medial nucleus of the thalamus (Kolb and Tees 1990)), PFC function in these species has been strongly linked to various aspects of cognition, especially working memory (Goldman Rakic 1999; Kesner 2000). Disturbances in the neuronal circuits subserving working memory have been proposed to underlie pathology of schizophrenia (Weinberger 1987; Goldman Rakic 1999), and recent genetic variation in a gene that impacts on working memory and prefrontal cortical function has been shown to increase susceptibility to schizophrenia (Egan et al. 2001; Weinberger et al. 2001).

Considering evidence that neuronal organization of PFC is altered in rats with the neonatal lesion of the ventral hippocampus, we tested the hypothesis that working memory is compromised in these animals. Previous studies assessed learning and working memory of animals with this neonatal lesion using a radial-arm maze and Morris water maze, tests strongly dependent on spatial recognition (Chambers et al. 1996, Le Pen et al. 2000). In both tests, the neonatally lesioned rats showed pronounced impairments; deficits in choice accuracy in a radial-arm maze test were apparent prepuberty, persisted into adulthood and were evident in both female and male rats with the neonatal hippocampal lesion (Chambers et al. 1996). In the present study, we examined the effect of the neonatal lesion on performance in two related working memory tasks: (1) the continuous delayed alternation (Brito et al. 1982); (2) the discrete paired-trial delayed alternation (Aultman and Moghaddam 2001), the relatively non-spatial tests because high walls of the maze in our tests reduced external cues. The former test is routinely used to evaluate working memory, but because it involves a regularly repeated sequence of events rather than trial-specific experience, its selective relationship to working memory has been questioned (Green and Stanton 1989). The latter test, on the other hand, requires frequent changes of strategy in response to recently acquired, randomly changing information, and therefore allows for a more reliable delay-dependent measure of working memory (Aultman and Moghaddam 2001).

\section{MATERIALS AND METHODS}

\section{Surgery}

All procedures were performed in accordance with the NIH guidelines for use and care of laboratory animals. Animals were on a 12-h light/dark cycle (lights on at 6:00 A.M.) in a temperature-controlled environment and with ad lib access to food and water. Female rats were purchased pregnant at 14 days of gestation (SpragueDawley, Harlan) and housed individually in breeding cages. Litters of four to eight male pups were formed at the time of surgery. Female pups were eliminated. Male rat pups were randomly assigned to lesion $(n=13$ and $\mathrm{n}=10$ in experiments 1 and 2, respectively) or sham ( $\mathrm{n}=$ 10 and $\mathrm{n}=8$, in experiments 1 and 2, respectively) status. Surgery was performed on postnatal day 7 (PD7) as previously described (Lipska et al. 1993). Rats were anesthetized by hypothermia (placing on wet ice for 10-20 $\mathrm{min}$ ) and then immobilized by taping onto a styrofoam platform fixed to a stereotaxic Kopf instrument (David Kopf Instruments, Tujunga, CA, USA). An incision was made in the skin overlying the skull. Ibotenic acid $(0.3 \mu \mathrm{l}, 3 \mu \mathrm{g})$ (Sigma Chemical Co.) (in the lesioned rats) or artificial cerebrospinal fluid (in the sham-operated rats) was bilaterally injected into the ventral hippocampus at a rate of $0.15 \mu \mathrm{L} / \mathrm{min}$ (coordinates: $\mathrm{AP}=$ $3.0 \mathrm{~mm}, \mathrm{ML}= \pm 3.5 \mathrm{~mm}, \mathrm{VD}=5.0 \mathrm{~mm}$, relative to bregma). The needle was left in place for $4 \mathrm{~min}$ to prevent diffusion of neurotoxin along the needle track, and then withdrawn. The skin incision was closed with staples. The pups were placed under a heating lamp, and returned to their mothers within half an hour after surgery. The pups were weaned at PD24, separated by lesion status, and housed 2-3 per cage. They were tested in adulthood, eight weeks post-lesion.

For experiments with the adult lesion, adult rats (Harlan Laboratories) (weighing 240-270 g, at approximately two months of age) were lesioned as previously described (Lipska et al. 1992). Rats were anesthetized with Equithesin $3 \mathrm{ml} / \mathrm{kg}$ (IP) and placed in a Kopf stereotaxic instrument using ear bars and a tooth bar $(-2.5 \mathrm{~mm})$. Ibotenic acid (total $6 \mu \mathrm{g} / 0.6 \mu \mathrm{L}$ in the lesioned animals, $\mathrm{n}=8$ and $\mathrm{n}=12$, in experiments 1 and 2, respectively) or artificial cerebrospinal fluid in sham rats $(n=8$ and $\mathrm{n}=9$, in experiments 1 and 2 , respectively) were administered into the ventral hippocampus at coordinates: $\mathrm{AP}=-4.4 \mathrm{~mm}, \mathrm{ML}= \pm 5.0 \mathrm{~mm}, \mathrm{VD}=-8.0$ and -6.0 $\mathrm{mm})$. Two injections of $0.3 \mu \mathrm{l}$ at a rate $0.2 \mu \mathrm{l} / \mathrm{min}$ were given on each side. The cannulae remained in place for 
4 min after the injection. Rats were tested six weeks postlesion by investigators blind to lesion status.

\section{Experiment 1. Continuous Spatial Delayed Alternation Task}

The first group of rats was tested in a continuous delayed alternation task in a T-maze as described elsewhere (Verma and Moghaddam 1996). The T-maze was constructed from plexiglass $(0.6 \mathrm{~cm}$ thick) and painted flat gray (dimensions: the main alley: $65 \times 14 \times 28 \mathrm{~cm}$, side alleys: $30 \times 14 \times 28 \mathrm{~cm}$ ). The side alleys were closed off from the main alley by movable doors. At the end of each side alley there was a 3-cm high barrier that concealed the food reward from view. The third movable door was mounted in the main alley. A holding cage $(50 \times$ $35 \times 28 \mathrm{~cm}$ ) was placed adjacent to the T-maze for use during the inter-trial intervals. A T-maze was cleaned between different animals but not between different trials. A food reward was one morsel of Froot Loops cereal. In this test, after the rat makes its first arm entry in the T-maze, it is subsequently rewarded for entering the arm opposite to the one entered on the previous trial during a succession of trials.

Rats were habituated to the maze for 7-10 days. First, animals were handled for three days prior to exposure to a T-maze. On two following consecutive days, each rat was allowed to explore the maze with all doors raised for $10 \mathrm{~min}$. Food was placed in both goal arms. Then animals were food restricted ( $15 \mathrm{~g}$ of food per rat per day) and remained that way throughout the experiment. After two days of food restriction, the adaptation process continued by placing the animal in each side arm with the doors closed, with food reward present at the end of the alley behind the barrier for $5 \mathrm{~min}$. The animal was then placed in the other arm for a 5-min stay. After this 7-10-day adaptation period, rats were trained as follows. During the first trial of each day, food was presented in both goal arms. During the next 10 trials, the arm opposite to the one the animal had entered on the previous trial was baited, except when the animal had gone to the empty arm on the last trial. In that case, the food was left in place and the baited side was changed only after the animal had alternated. Ten seconds after entry to the arm, the animal was removed and returned to the holding cage for a $10 \mathrm{~s}$ inter-trial interval. This training continued until a criterion of $80 \%$ correct choices (in 10 trials) on two consecutive days was achieved. A maximum of 200 trials (over 20 days) was given.

The data were analyzed by ANOVA with Lesion status and Day as independent factors because of the varying numbers of animals per day (those animals that reached the criteria were not tested further) followed by Fisher PLSD post-hoc tests. Comparison of the number of rats that reached the criteria in the neonatal lesion group versus sham-operated controls and the adult lesion group was done by nonparametric Fisher exact tests. The level of significance was set at $p<.05$.

\section{Experiment 2. Discrete Paired-trial Variable-delay Task}

A second group of neonatal and adult lesioned rats was tested in a discrete paired-trial variable-delay T-maze task (Freeman and Stanton 1991; Aultman and Moghaddam 2001). In this task, animals were presented with a sequence of randomly chosen forced runs, each followed by a choice run.

Following 7-10 days of habituation (same as above), animals were exposed to 10 forced-alternation runs per day for 3-5 days. Next, the discrete-trial delayed alternation training began. Following a randomly chosen forced run, and a 10 s delay interval in the holding cage, the animal was placed back in the maze with access to both arms but with bait only in the opposite arm to the one entered in the previous forced run. Once the animal entered a choice arm, a door to that arm was closed off. After an inter-trial period of $15 \mathrm{~s}$, the animal was placed back in the maze for another forced run. A different randomly chosen pattern of forced runs (e.g., R-R-L-RL-L-R-L-R-L) was used everyday but on a given day the same pattern was used for all animals. The $10 \mathrm{~s}$ delayedalternation task was presented to each animal for 10 days, at which time all animals successfully reached the criterion of stable performance (i.e. delayed alternation varied less than $10 \%$ in five consecutive days). Once animals performed consistently at $10 \mathrm{~s}$ delay, they were tested at three delays $(1,10$ and $40 \mathrm{~s}$ presented in a random fashion) for five consecutive days.

The data (\% correct choices) from the neonatal and adult lesion groups were analyzed separately by a 3-way ANOVA with Lesion as an independent variable, and Delay $(1,10,40 \mathrm{~s})$ and Day (1-5) as repeated factors. Fisher PLSD tests were used for post-hoc comparisons.

At the completion of the study, animals were perfused under deep anesthesia, brains were removed, sectioned into $40 \mu \mathrm{m}$ slices, and Nissl-stained for verification of the lesion.

\section{RESULTS}

Verification of lesions using Nissl-stained sections revealed cell loss and gliosis throughout the ventral hippocampus as previously reported (Lipska et al. 1992; Lipska et al. 1993; Khaing et al. 2000). While the dorsal hippocampus was spared, there was neuronal loss, atrophy and cavitation in the ventral hippocampus with damage detected in portions of the subiculum and posterior dentate gyrus. Five animals were excluded from the final analysis of the behavioral data due to the mis- 
placement of the lesion (two rats with the neonatal lesion and one rat with the adult lesion (damage in the amygdala and/or the neocortex) in experiment 1 , and one animal with the neonatal lesion (damage in the thalamus) and one rat with the adult lesion (damage in the neocortex) in experiment 2). There were no differences between the neonatal and adult lesions (Figure 1).

\section{Experiment 1. Continuous Spatial Delayed Alternation Task}

The daily performance of rats with the neonatal ventral hippocampal lesion in the continuous delayed alternation task was worse than the sham-operated rats (Figure 2). Analysis of the number of correct choices in the training period from 7 to 16 days (the end of the period is the day by which all the sham animals reached criteria and thus completed the testing) showed that there was a significant effect of Lesion $\left(\mathrm{F}_{1,181}=11.5, p<.05\right)$ and Day $\left(\mathrm{F}_{9,181}=5.8, p<.05\right)$ and a significant Lesion $\mathrm{X}$ Day interaction $\left(\mathrm{F}_{9,181}=3.1, p<.05\right)$. Post-hoc analysis revealed that initially, there was no difference in performance between the lesioned rats and control animals. However, by day 11, control rats began to rapidly improve their performance, whereas the neonatally lesioned animals continued to perform at just above chance levels (Figure 2). The average number of days taken to reach $80 \%$ correct choices for the four groups is indicated in Table 1. All sham-operated animals reached the criterion before day 20 (i.e., before the 200 trial limit). An ANOVA showed that the neonatally lesioned rats that were able to learn the task (i.e., performed at $80 \%$ correct choices for two consecutive days) required significantly longer time to do so than the sham-operated rats $\left(\mathrm{F}_{3,24}=2.2, p<.05\right)$, Table 1 . Fisher exact tests

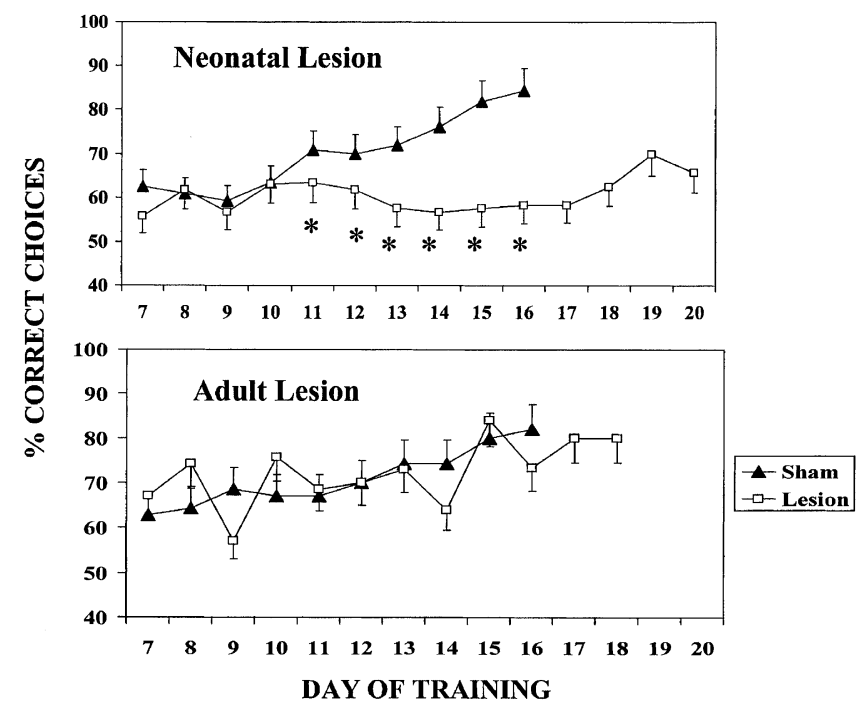

Figure 2. Daily performance in the T-maze continuous spatial alternation task in adult rats with the neonatal lesion of the ventral hippocampus (upper panel) and in rats with the adult lesion of the ventral hippocampus (lower panel). The $X$ axis represents the number of days from the start of delayed alternation training. Each animal was given 10 choices per day with an inter-trial interval of $10 \mathrm{~s}$. Rats were trained until the criterion of $80 \%$ correct choices on two consecutive days was reached. Starting at training day 11, rats with the neonatal lesion showed significantly worse performance than sham controls $(* p<.05)$. A similar lesion produced in adulthood did not result in impaired performance in this task.

revealed that the number of individuals that mastered the task in the neonatal lesioned group was significantly lower as compared with the neonatal sham group $(p<$ $.001)$ or the adult lesioned group $(p<.05)$.
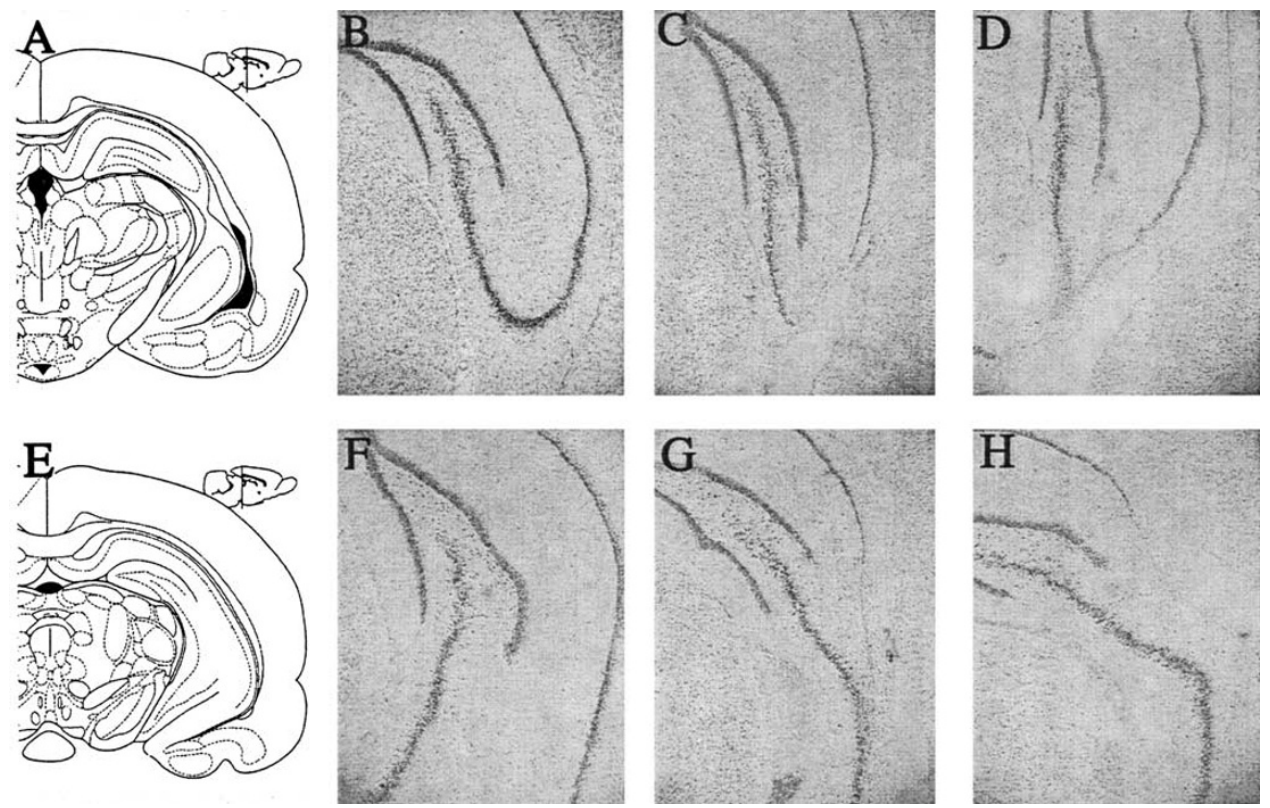

Figure 1. A sham $(\mathrm{B}, \mathrm{F})$, neonatal $(C, G)$ and adult $(D, H)$ excitotoxic lesion of the ventral hippocampus shown in photomicrographs of Nissl-stained brain sections through the hippocampus of an adult rat at the anterior-posterior level corresponding to bregma -4.4 $\mathrm{mm}(\mathrm{A})$ and $-5.6 \mathrm{~mm}$ (E) (diagrams adapted from the atlas of Paxinos and Watson (1986)). 
Table 1. The Number of Days Taken to Reach the Criterion of $80 \%$ Correct Choices on Two Consecutive Days in the Continuous Delayed Alternation Task

\begin{tabular}{lccc}
\hline Treatment & $\begin{array}{c}\text { N } \\
\text { (total) }\end{array}$ & $\begin{array}{c}\text { N } \\
\text { (that reached } \\
\text { criteria) }\end{array}$ & $\begin{array}{c}\text { Days to } \\
\text { reach criteria } \\
\text { (Mean } \pm \text { SD) }\end{array}$ \\
\hline Neonatal Lesion & 11 & 3 & $18.0 \pm 2.0^{*}$ \\
Neonatal Sham & 10 & 10 & $14.6 \pm 0.6$ \\
Adult Lesion & 7 & 6 & $15.5 \pm 1.1$ \\
Adult Sham & 8 & 6 & $15.0 \pm 0.8$ \\
\hline
\end{tabular}

${ }^{*} p<.05$ as compared with the Neonatal Sham group.

In contrast to the neonatal lesion, the adult lesion of the ventral hippocampus did not impair the rate of acquisition in the T-maze delayed alternation task. Adult lesioned animals reached criteria at the same rate as the adult sham-operated rats (Figure 2, Table 1).

\section{Experiment 2. Discrete Paired-trial Variable-delay Task}

Since the failure to learn the continuous alternation task by the neonatally lesioned rats may be interpreted as impaired acquisition or sensory integration, or other non-mnemonic processes, we examined delay-dependent performance in a discrete paired-trial delayed alternation task.

All animals reached the criterion of stable performance in this task (Figure 3 and Figure 4). However, in comparing the performance of the neonatally lesioned and sham groups, a 3-way ANOVA revealed a significant effect of Lesion $\left(\mathrm{F}_{1,112}=51.8, p<0001\right)$, Delay $\left(\mathrm{F}_{2,112}=226.29, p<.0001\right)$ and Day $\left(\mathrm{F}_{4,112}=3.8, p<\right.$ $.001)$ as well as a significant Lesion $\times$ Delay $\times$ Day in- teraction $\left(\mathrm{F}_{8,112}=3.6, p<.001\right)$. Thus, the performance of the neonatally lesioned rats was worse at increasing delays, was significantly worse than the sham-operated animals at all delays $(p<.05)$, but was stable, i.e., their performance did not improve over time.

In contrast, the adult ventral hippocampal lesion did not impair performance in the discrete trial delayed alternation. An ANOVA showed no significant effect of Lesion $\left(\mathrm{F}_{1,136}=0.15, p>.5\right)$. There were significant effects of Day $\left(\mathrm{F}_{4,136}=4.6, p<.01\right)$ and Delay $\left(\mathrm{F}_{2,136}=206.2\right.$, $p<.0001$ ), indicating some improvement of performance in both groups (sham and lesion) over time and significantly worse performance in both groups at increasing delays $(p<.05)$. There was no significant interaction between Lesion, Delay and Day $\left(\mathrm{F}_{8,136}=0.8, p>.5\right)$.

\section{DISCUSSION}

The present study demonstrates that an excitotoxic neonatal lesion of the ventral hippocampus impairs working memory in behavioral tasks that are dependent on the functional integrity of PFC (e.g. Sanchez-Santed et al. 1997; Aultman and Moghaddam 2001). In the continuous delayed alternation task, the majority of the neonatally lesioned animals did not reach the performance criterion of $80 \%$ correct choices in two consecutive days. In the discrete trial task, where the criterion was stable performance irrespective of choice accuracy, all neonatally lesioned animals reached the criterion. However, the accuracy of performance in these animals was significantly worse than sham controls, suggesting that while the lesioned animals were motivated and able to perform the task, their working memory capacity was compromised.

Animals with adult lesions of the ventral hippocampus were not impaired in either task, suggesting that

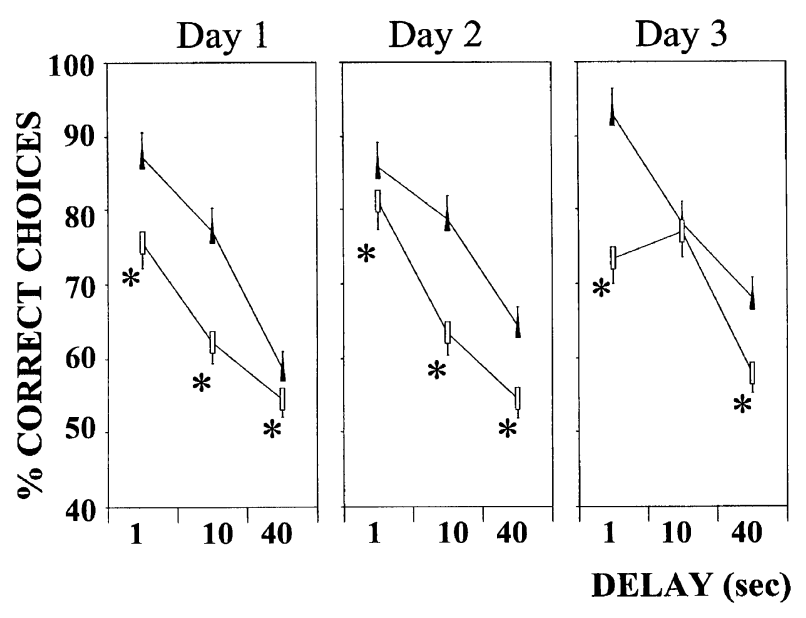

Day 4

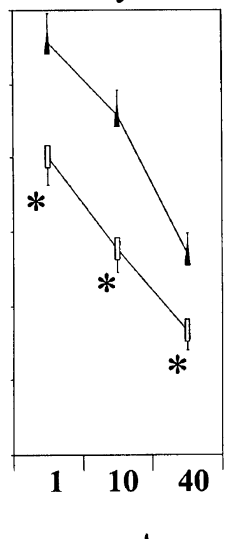

Day 5

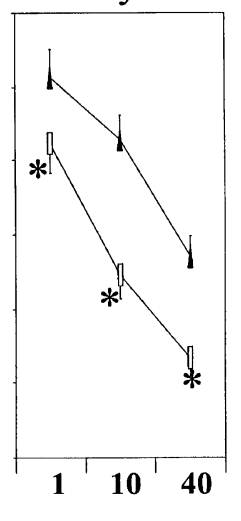

Figure 3. Daily performance in the discrete trial delayed alternation task in adult rats with the neonatal lesion of the ventral hippocampus. The animals were trained (see Methods) and then tested in the T-maze at three delays 1,10 and $40 \mathrm{~s}$ presented in a random fashion during the next five days. Rats with the neonatal lesion performed significantly worse than controls at all delays $\left({ }^{*} p<.05\right)$. 


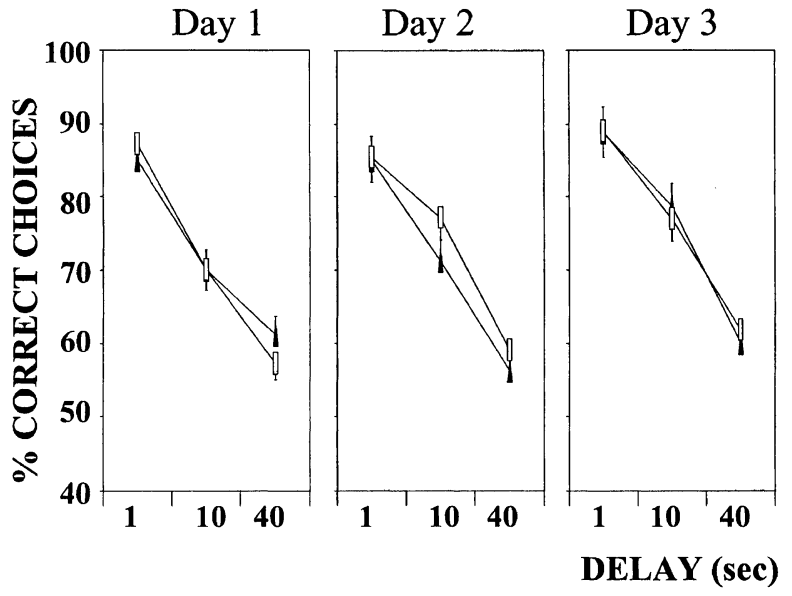

the ventral hippocampus per se is not necessary for delayed alternation performance. However, the pattern of impaired performance of the neontally lesioned animals in the discrete trial task is similar to the performance of animals with adult lesions of mPFC (Aultman and Moghaddam 2001), consistent with other evidence (see the introduction) of a functional abnormality of PFC in these animals.

Previous studies in the rodent and primate have indicated that adult hippocampal lesions may be sufficient to disrupt the performance in behavioral paradigms that involve spatial memory (Olton and Pappas 1979; Kesner and DiMattia 1987). One possible explanation for the discrepancy between our results and previous findings is that the hippocampal lesions in our study were small and restricted to the ventral portion. However, some studies of the small reversible lesions (e.g., lidocaine infusions) of the ventral hippocampus showed that these lesions can also disrupt performance on spatial tasks (Floresco et al. 1997; Poucet and Buhot 1994). Another possibility is that the hippocampus is not critical for the performance of delayed alternation tasks that are relatively non-spatial or that involve relatively short delays (lasting for seconds in our tests rather than minutes or hours). Chambers and colleagues (1996) using spatial radial-arm maze tests, have reported working memory deficits after a neonatal ventral hippocampal lesion in rats whose training started at various developmental stages - before puberty (PD25), during adolescence (PD40) and in adulthood (PD80). The lesioned rats showed consistent deficits irrespective of age at testing or gender. In those studies, prepubertal rats that did not display motor abnormalities were similarly cognitively impaired as rats trained in adulthood that were hyperactive; hence, this finding argues against the possibility that disruption of motor function is responsible for poor performance in the working memory tasks. The findings of Le Pen et al. (2000), who showed learning impairments in rats with the neonatal hippocampal lesion in the Morris water maze and in avoidance tasks, but no motor deficits during swim or in strength tests, further support the notion that motor abilities are not responsible for impaired cognitive performance in this model.

Taken together, the present findings indicate that an insult to the ventral hippocampus during development disturbs the associative functions of PFC (a brain region that matures late and shows an array of molecular and physiological anomalies in the neonatally lesioned animals) and/or functions of the remaining hippocampus or other critical regions (Floresco et al. 1997, 1999), more profoundly than if it had occurred during adulthood. These findings are consistent with previous reports that temporolimbic development affects the ontogeny of working memory (Freeman and Stanton 1991, 1992; Green and Stanton 1989), and that the neonatal hippocampal lesions may have widespread and lasting adverse effects in the interconnected areas implicated in certain cognitive processes (Van Praag et al. 1998; Khaing et al. 2000; Chambers et al. 1996; Le Pen et al. 2000).

The characteristics of the changes in the neonatally lesioned rats may provide some clues about the neurotransmitter systems that are compromised in these animals. For instance, the pattern of impairment seen in the discrete trial task is similar to that observed after exposure to scopolamine (Aultman and Moghaddam 2001), suggesting that cholinergic systems may be affected. This speculation is consistent with animal and human studies implicating cortical cholinergic neurotransmission in sustaining working memory and related associative functions, such as attention and behavioral activation (Everitt and Robbins 1997; Steckler et al. 1998; Furey et al. 2000). The cholinergic system has not been directly investigated in these animals, however. 
Dopaminergic projections to PFC are also implicated in proper working memory function (Williams and Goldman Rakic 1995). Although it is possible that the neonatal lesion of the hippocampus disrupts PFC function by altering dopaminergic neurotransmission, neurochemical findings do not provide consistent support for this contention (Lipska and Weinberger 2000). In addition, behavioral pharmacological investigations have shown that disruption of the dopamine system produces a somewhat different pattern of impairment in the discretetrial task than that observed here: deficits are apparent selectively at delays of $10 \mathrm{~s}$ or more (Aultman and Moghaddam 2001). This is in agreement with findings that tonic dopaminergic activity may not contribute to the delayed alternation performance in the rat; rather, dopamine seems to play a modulatory role in association with excitatory amino acids (Verma and Moghaddam 1996; Adams and Moghaddam 1998). Notably, the neonatal hippocampal lesion alters the metabolic properties of pyramidal glutamate neurons as suggested by reduced levels of prefrontal N-acetylasparate (NAA) in young adult but not pre-pubertal rats (Bertolino et al. 1999). Moreover, physiological responses of prefrontal pyramidal neurons following stimulation of dopaminergic neurons in the brainstem are altered in adult but not prepubertal rats with the neonatal hippocampal lesion (O'Donnell et al. 1999). Similarly to the delayed alternation deficits, this aberrant response of prefrontal neurons to dopamine is not seen after an identical adult lesion of the ventral hippocampus. These data suggest that the tuning response of prefrontal pyramidal neurons by dopamine, which may be a necessary component for spatial working memory performance (Williams and Goldman-Rakic 1995), may be uniquely disrupted by a developmental hippocampal insult.

In conclusion, we used an animal model to examine whether a developmental insult in a brain region implicated as a site of pathology in schizophrenia (Weinberger 1999) produces working memory deficits. We found that the neonatal lesion of the ventral hippocampus impaired working memory performance in a way that resembled the pattern of performance observed previously in animals with discrete lesions of mPFC. This behavioral abnormality was in contrast to that observed in animals with adult lesions of the ventral hippocampus, suggesting that a hippocampal early developmental defect produces a pattern of behavioral changes reflective of impaired associative functions of PFC.

\section{ACKNOWLEDGMENTS}

This work was supported, in part, by PHS award MH48404, MH01616, and the Veterans Administration Center for Schizophrenia. We thank Mr. Daniel Lerman and Mr. Nader Halim for their excellent technical assistance.

\section{REFERENCES}

Adams B, Moghaddam B (1998): Corticolimbic dopamine neurotransmission is temporally dissociated from the cognitive and locomotor effects of phencyclidine. J Neurosci 18:5545-5554

Aultman JM, Moghaddam B (2001): Distinct contributions of glutamate and dopamine receptors to temporal aspects of rodent working memory using a clinically relevant task. Psychopharmacology (Berl) 153:353-364

Bachevalier J, Alvarado MC, Malkova L (1999): Memory and socioemotional behavior in monkeys after hippocampal damage incurred in infancy or in adulthood. Biol Psychiatry 46:329-339

Becker A, Grecksch G, Bernsteinn H-G, Hollt V, Bogerts B (1999): Social behavior in rats lesioned with ibotenic acid in the hippocampus: quantitative and qualitative analysis. Psychopharmacology (Berl) 144:333-338

Bertolino A, Saunders RC, Mattay VS, Bachevalier J, Duyn JH, Frank JA, Weinberger DR (1997): Altered development of prefrontal neuronal chemistry in rhesus monkeys with neonatal mesial temporo-limbic lesions: A proton magnetic resonance spectroscopic imaging study. Cereb Cortex 7:740-748

Bertolino A, Roffman JL, Lipska BK, Van Gelderen P, Olson A, Weinberger DR (1999): Postpubertal emergence of prefrontal neuronal deficits and altered dopaminergic behaviors in rats with neonatal hippocampal lesions. Soc Neurosci Abstract 25:1294

Brito GN, Thomas GJ, Davis BJ, Gingold SI (1982): Prelimbic cortex, mediodorsal thalamus, septum, and delayed alternation in rats. Exp Brain Res 46:52-58

Carr DB, Sesack SR (1996): Hippocampal afferents to the rat prefrontal cortex: synaptic targets and relation to dopamine terminals. J Comp Neurol 369:1-15

Chambers RA, Moore J, McEvoy JP, Levin ED (1996): Cognitive effects of neonatal hippocampal lesions in a rat model of schizophrenia. Neuropsychopharmacology 15:587-594

Egan MF, Goldberg TE, Kolachana B, Mazzanti C, Callicott J, Straub R, Goldman D, Weinberger DR (2001): Effect of COMT genotype on frontal lobe function and risk for schizophrenia. Proc Natl Acad Sci 98:6917-6922

Everitt BJ, Robbins TW (1997): Central cholinergic systems and cognition. Annu Rev Psychol 48:649-684

Floresco SB, Seamans JK, Phillips AG (1997): Selective roles for hippocampal, prefrontal cortical, and ventral striatal circuits in radial-arm maze tasks with or without a delay. J Neurosci 17:1880-1889

Floresco SB, Braaksma DN, Phillips AG (1999): Thalamiccortical-striatal circuitry subserves working memory during delayed responding on a radial arm maze. J Neurosci 19:11061-11071

Freeman JH Jr, Stanton ME (1991): Fimbria-fornix transections disrupt the ontogeny of delayed alternation but not position discrimination in the rat. Behav Neurosci 105:386-395

Freeman JH Jr, Stanton ME (1992): Medial prefrontal cortex lesions and spatial delayed alternation in the developing rat: recovery or sparing? Behav Neurosci 106:924-932

Furey ML, Pietrini P, Haxby JV (2000): Cholinergic enhance- 
ment and increased selectivity of perceptual processing during working memory. Science 290:2315-2319

Goldman-Rakic PS (1999): The physiological approach: Functional architecture of working memory and disordered cognition in schizophrenia. Biol Psychiatry 46:650-661

Green RJ, Stanton ME (1989): Differential ontogeny of working memory and reference memory in the rat. Behav Neurosci 103:98-105

Jay TM, Witter MP (1991): Distribution of hippocampal CA1 and subicular efferents in the prefrontal cortex of the rat studied by means of anterograde transport of Phaseolus vulgaris-leucoagglutinin. J Comp Neurol 313:574-586

Kesner RP (2000): Subregional analysis of mnemonic functions of the prefrontal cortex in the rat. Psychobiology 28:21119-21228

Kesner RP, DiMattia BV (1987): Neurobiology of an attribute model of memory. Prog Psychobiol Physiol Psychol 12:207-277

Khaing ZZ, Weickert CS, Weinberger DR, Lipska BK (2000): Differential DNA damage in response to the neonatal and adult excitotoxic hippocampal lesion in rats. Eur J Neurosci 12:4424-4433

Kolb B, Tees RC (1990): The rat as a model of cortical function. In Kolb B, Tees RC (eds), The Cerebral Cortex of the Rat. Cambridge, MA, A Bradford Book, The MIT Press, pp 3-17

Le Pen G, Gorttick AJ, Higgins GA, Martin JR, Jenck F, Moreau J-L (2000): Spatial and associative learning deficits induced by neonatal excitotoxic hippocampal damage in rats: further evaluation of an animal model of schizophrenia. Behav Pharm 11:257-268

Lipska BK, Jaskiw GE, Chrapusta SJ, Karoum F, Weinberger DR (1992): Ibotenic acid lesion of the ventral hippocampus differentially affects dopamine and its metabolites in the nucleus accumbens and prefrontal cortex in the rat. Brain Res 585:1-6

Lipska BK, Jaskiw GE, Weinberger DR (1993): Postpubertal emergence of hyperresponsiveness to stress and to amphetamine after neonatal hippocampal damage: A potential animal model of schizophrenia. Neuropsychopharmacology 9:67-75

Lipska BK, Weinberger DR (1994): Gonadectomy does not prevent novelty- or drug-induced hyperresponsiveness in rats with neonatal excitototxic hippocampal damage. Dev Brain Res 78:253-258

Lipska BK, Jaskiw GE, Braun AR, Weinberger DR (1995a): Prefrontal cortical and hippocampal modulation of haloperidol-induced catalepsy and apomorphine-induced stereotypic behaviors in the rat. Biol Psychiatry 38:255-262

Lipska BK, Swerdlow NR, Geyer MA, Jaskiw GE, Braff DL, Weinberger DR (1995b): Neonatal excitotoxic hippocampal damage in rats causes postpubertal changes in prepulse inhibition of startle and its disruption by apomorphine. Psychopharmacology (Berl) 122:35-43

Lipska BK, Al-Amin HA, Weinberger DR (1998): Excitotoxic lesions of the rat medial prefrontal cortex: effects on abnormal behaviors associated with neonatal hippocampal damage. Neuropsychopharmacology 19:451-464

Lipska BK, Weinberger DR (2000): To model a psychiatric disorder in animals. Schizophrenia as a reality test. Neuropsychopharmacology 23:223-239
Lipska BK, Weinberger DR, Kolb B (2000): Synaptic pathology in prefrontal cortex and nucleus accumbens of adult rats with neonatal hippocampal damage. Abstract American College on Neuropsychopharmacology 39:209

O’Donnell P, Lewis BL, Lerman D, Weinberger DR, Lipska BK (1999): Effects of neonatal hippocampal lesions on prefrontal cortical pyramidal cell responses to VTA stimulation. Soc Neurosci Abstract 25:1569

Olton DS, Pappas BC (1979): Spatial memory and hippocampal function. Neuropsychologia 17:669-682

Paxinos G, Watson C (1986): The Rat Brain in Stereotaxic Coordinates. Sydney, Academic Press

Poucet B, Buhot MC (1994): Effects of medial septal or unilateral hippocampal inactivations on reference and working spatial memory in rats. Hippocampus 4:315-321

Sams-Dodd F, Lipska BK, Weinberger DR (1997): Neonatal lesions of the rat ventral hippocampus result in hyperlocomotion and deficits in social behaviour in adulthood. Psychopharmacology (Berl) 132:303-310

Sanchez-Santed F, De Bruin JPC, Heinsbroek RPW, Verwer RWH (1997): Spatial delayed alternation of rats in a T-maze: effects of neurotoxic lesions of the medial prefrontal cortex and of T-maze rotation. Behav Brain Res 84:73-79

Saunders RC, Kolachana BS, Bachevalier J, Weinberger DR (1998): Neonatal lesions of the medial temporal lobe disrupt prefrontal cortical regulation of striatal dopamine. Nature 393:169-171

Schroeder H, Grecksch G, Becker A, Bogerts B, Hoellt V (1999): Alterations of the dopaminergic and glutamatergic neurotransmission in adult rats with postnatal ibotenic acid hippocampal lesion. Psychopharmacology (Berl) 145:61-66

Steckler T, Sahgal A, Aggleton JP, Drinkenburg WH (1998): Recognition memory in rats - III. Neurochemical substrates. Prog Neurobiol 54:333-348

Swerdlow NR, Lipska BK, Weinberger DR, Braff DL, Jaskiw GE, Geyer MA (1995): Increased sensitivity to the sensorimotor gating-disruptive effects of apomorphine after lesions of frontal cortex or hippocampus in adult rats. Psychopharmacology (Berl) 122:27-34

van Praag H, Qu PM, Elliott RC, Wu H, Dreyfus CF, Black IB (1998): Unilateral hippocampal lesions in newborn and adult rats: effects on spatial memory and BDNF gene expression. Behav Brain Res 92:21-30

Verma A, Moghaddam B (1996): NMDA receptor antagonists impair prefrontal cortex function as assessed via spatial delayed alternation performance in rats: modulation by dopamine. J Neurosci 16:373-379

Weinberger DR (1987): Implications of normal brain development for the pathogenesis of schizophrenia. Arch Gen Psychiatry 44:660-669

Weinberger DR (1999): Cell biology of the hippocampal formation in schizophrenia. Biol Psychiatry 45:395-402

Weinberger DR, Egan MF, Bertolino A, Callicott JH, Mattay VS, Lipska BK, Berman KF, Goldberg TE (2001): Prefrontal neurons and the genetics of schizophrenia. Biol Psychiatry 50:825-844

Williams GV, Goldman-Rakic PS (1995): Modulation of memory fields by dopamine D1 receptors in prefrontal cortex. Nature 376:572-575 